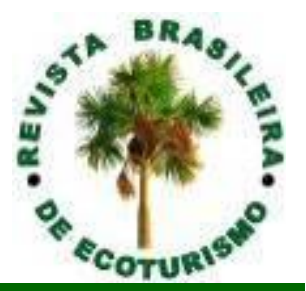

\title{
Perspectivas para o desenvolvimento do turismo na Reserva de Desenvolvimento Sustentável de Barra Una (SP)
}

\section{Perspectives for tourism development in the Barra do Una Sustainable Development Reserve (SP, Brazil)}

\author{
Alisson Peter Brito Dopona, Renato Xavier Araújo Prudêncio, Milena Ramires, \\ Mariana Clauzet
}

\begin{abstract}
RESUMO: Reserva de Desenvolvimento Sustentável (RDS) é uma categoria de Unidade de Conservação destinada a preservar a natureza e abrigar populações locais, dando condições para resiliência, qualidade de vida e manejo dos recursos naturais. $O$ objetivo deste artigo foi analisar o potencial turístico da Reserva de Desenvolvimento Sustentável de Barra do Una (RDSBU), através da investigação da infraestrutura local, das demandas, expectativas e do Conhecimento Ecológico Local da comunidade relacionadas aos atrativos naturais existentes na RDSBU, visando subsidiar 0 planejamento de futuras atividades turísticas no local. Foram entrevistados 25 moradores de ambos os gêneros, com idade média de 47 anos, residentes há mais de duas gerações que responderam questionários semiestruturados entre 2013 e 2014. 14 atrativos com potencial turístico foram indicados, dos quais sete tiveram maior frequência de citações, incluindo praias, cachoeiras, rios e costão rochoso, sendo que duas, das 7 localidades encontram-se em área de proteção integral (Estação Ecológica). Para o desenvolvimento do turismo na RDSBU destaca-se a necessidade da melhoria de infraestrutura, incluindo o acesso à Vila, saneamento, energia e comunicação. Somado a beleza natural da Mata Atlântica que cerca a RDSBU como um atrativo, ficou evidente a expectativa dos moradores e o potencial para o turismo.
\end{abstract}

PALAVRAS CHAVE: Unidade de Conservação; Reserva de Desenvolvimento Sustentável; Sociedade e Turismo.

ABSTRACT: Sustainable Development Reserve (SDR) is a category of Conservation Units destined to preserve nature and shelter local populations, providing conditions for resilience, life quality and natural resources management. The aim of this paper was to analyze the Barra da Una SDR (BUSDR) touristic potential by investigating the local infrastructure as also demands, expectations, and Local Ecological Knowledge related to the natural attractives existing in the BUSDR, in order to support the planning of future local tourism activities. Twenty-five residents of both genders, with an average age of 47 years resident for more than two generations, were interviewed and answered semistructured questionnaires between 2013 and 2014. Fourteen attractives with touristic potential were indicated, of which seven had the highest frequency of citations, including beaches, waterfalls, rivers and the rocky shore, two of the seven locations are in the full protection area (Ecological Station). In the development of tourism in BUSDR, the need to improve infrastructure, including access to the village, sanitation, energy and communication, is highlighted. Adding to the natural beauty of the Atlantic Rainforest that surrounds the BUSDR as an attraction, it is evident the residents' expectation and the potential for tourism.

KEYWORDS: Protect Areas; Sustainable Development Reserve; Society and Tourism. 


\section{Introdução}

A população que habita a costa do Brasil nos estados de São Paulo, Paraná e parte do Rio de Janeiro pode ser denominada como caiçaras, que tem em comum a origem na miscigenação de índios, negros e colonos portugueses e tradicionalmente, sobrevivem de práticas agrícolas e pesca (DIEGUES, 1973; 1988; SILVA; DIEGUES, 1993). A população residente na Reserva de Desenvolvimento Sustentável (RDS) da Barra do Una (RDSBU) é uma população caiçara que atualmente sobrevive da pequena pesca e atividades relacionadas ao turismo, especialmente aluguel de casas para temporada e a pesca esportiva.

A luta pela conservação dessa região, se iniciou em 1958, com a criação da Reserva Estadual do Itatins pelo Decreto Estadual $n^{\circ} 31.650$ e alcançou seu auge em 1986 com a criação da Estação Ecológica Juréia-Itatins (EEJI), despontando movimentos ambientalistas nacionais e internacionais em contraponto ao Acordo Nuclear Brasil/Alemanha no qual eram previstos incentivos do governo federal para instalar usinas nuclear na região (NUNES, 2003).

Contudo, regulamentada pela Lei Estadual 5.649 de 28 de abril de 1987, a EEJI não obedecia aos critérios para a criação dessa categoria de Unidade de Conservação (UC), pois só poderiam ser implementadas em áreas de domínio público ou desapropriadas, desconsiderando assim direito a terra dos moradores ali residentes. A partir daí, se iniciou uma série de conflitos entre moradores locais e Estado que em alguns casos, segundo Rosa (2007, p. 17) eram "caracterizados como abuso de poder por técnicos, guarda-parques e polícia florestal'.

Ao longo do tempo até os últimos anos, a Vila Barra do Una teve o status de UC determinada pelo Sistema Nacional de Unidades de Conservação (SNUC Lei 9.985/2000) constantemente alterado entre Estação Ecológica e Reserva de Desenvolvimento Sustentável, gerando diversos conflitos aos moradores, uma vez que estas categorias são totalmente distintas em relação às normas de uso dos recursos naturais locais e ocupação do território.

Conforme previsto no SNUC, as Estações Ecológicas integram as UCs de Proteção Integral: são de domínio público, e as áreas particulares precisam ser desapropriadas. Nesta categoria não é permitida nenhuma forma de uso dos recursos naturais da área a ser preservada. Já as RDSs, são UCs de Uso Sustentável, também de domínio público prevê a desapropriações eventuais, permitindo abrigar populações locais que vivem dentro da área e fornecer as condições para reprodução dos modos de exploração dos recursos naturais (BRASIL, 2000).

Nas RDSs podem ser desenvolvidas diversas atividades como, por exemplo, pesquisa científica voltada à conservação da natureza, atividades de educação ambiental, exploração e manejo dos recursos naturais, a substituição da cobertura vegetal por espécies cultiváveis e visitação pública, desde que todas estas atividades estejam autorizadas pelo órgão gestor e compatíveis com o interesse da população local, ao zoneamento e com o Plano de Manejo da UC (BRASIL, 2000).

O processo de criação da categoria de UC denominada RDS, surgiu no Estado do Amazonas, em 1996, em Mamirauá no médio Solimões, com uma situação conflituosa semelhante à EEJI, com o intuito de manter as comunidades locais em suas terras, além de dar a oportunidade de explorarem os recursos 
naturais de uma maneira sustentável. Mais tarde, em 2000, esta categoria foi incluída no SNUC (LOPES et. al, 2011).

Em relação a RDSBU, no ano de 2006 foi apresentado o projeto de Lei no 12.406, modificando as áreas que formavam a EEJI, criando o Mosaico de Unidades de Conservação Juréia-Itatins (MUCJI), regulamentando assim as ocupações dos territórios e os respectivos usos de recursos naturais incluídos em uma variedade de UC's. Porém, em 2009 o projeto foi julgado como Ação Direta de Inconstitucionalidade (ADIN), pois foi posta em dúvida a conservação do meio ambiente no mosaico. Além disto, foi argumentado também que houve a "indispensabilidade do Estudo de Impacto Ambiental que afronta aos artigos $5^{\circ}, 24$, 111, 144, 191 e 196, todos estes da Constituição Estadual". Novamente em 2013, um novo projeto de lei, no 14.982, foi enviado para alterar o status da UC, mas sem efeito, a Barra do Una volta-se como Estação Ecológica em 10 de Dezembro de 2013, quando foi julgado novamente como ADIN, pois "viola o princípio da proibição do retrocesso ambiental [...] que não é possível a transformação de unidade de conservação de proteção integral, em nenhum tipo de unidade de conservação de uso sustentável' (SÃO PAULO-DIÁRIO OFICIAL, 2013, p. 609). Com isso, a Barra do Una voltou a fazer parte da EEJI, tirando direitos à terra e às atividades econômicas relacionadas ao uso de recursos naturais. Finalmente, em junho de 2014, a ADIM foi julgada improcedente por votação unânime enfatizando-se que: "recolha-se, por ora, os mandados de desocupação e demolição que ainda não tenham sido cumpridos" (SÃO PAULO-DIÁRIO OFICIAL, 2014, p. 22-46), e a Barra do Una foi então reclassificada como RDS, como segue categorizada até hoje.

Uma das principais consequências desta histórica instabilidade, é a desconfiança e descrença dos moradores locais nos órgãos públicos gestores, influenciando negativamente em processos participativos de planejamento ordenado das atividades de uso dos recursos naturais. Ferreira (2015), em seu trabalho na região, comenta sobre a impressão de que as instituições públicas de meio ambiente tratam temas complexos com "muita simplicidade" no que tange a execução e gestão da RDSBU. Além disto, quando a parceria entre gestores e usuários não está consolidada e os usos dos recursos naturais advindo de atividades tradicionais ali desenvolvidas não estão "ajustados" à categoria da UC, os objetivos de conservação de determinada área protegida ficam comprometidos muitas vezes inclusive, resultando em atos ilegais por parte das populações locais. Como destacaram Begossi et al., (2011), nestas situações, os usuários precisam fazer escolhas entre aderir a conservação ambiental ou a subsistência.

Muitos trabalhos demonstram o sucesso das UCs de Uso Sustentável em termos de conservação de recursos naturais e sociais. Em sistemas de gestão pesqueira conduzidos por comunidades de pescadores artesanais, por exemplo, diversos autores destacam a eficiência do compartilhamento de direitos e responsabilidades comuns entre os usuários, que regem o acesso e o controle à exploração dos recursos naturais (MCKEAN; OSTROM, 1995; AGRAWAL, 2001; CARLSSON; BERKES, 2005; OSTROM, 2009). Contudo, na contramão de iniciativas bem-sucedidas, no Brasil, as UCs de Uso Sustentável, especialmente nas categorias de RDSs e Reservas Extrativistas Marinhas (RESEXs), são estabelecidas por ações "top down", implementadas sem consultar as comunidades locais, o que para Teixeira, Mariz, de Souza e Campos (2016) marginaliza a valiosa contribuição dos usuários no planejamento de gestão dessas áreas. Para Lopes et al., (2013), as políticas de modelo "top-down" criam uma mentalidade de "aproveitamento máximo" 
nos usuários, que gera problemas para os investimentos públicos exigidos na implementação e monitoramento de políticas públicas no campo ambiental. Por fim, vale destacar que grande parte das áreas protegidas no Brasil não possui Plano de Manejo (PM) instituído, o que é o principal instrumento de gestão destas áreas. Santos e Schiavetti (2014), por exemplo, analisaram mais de 20 RESEXs Marinhas ao longo do litoral brasileiro sob vários aspectos e concluem que é latente a carência da presença do Estado no apoio institucional tanto na criação, quanto na gestão destas UCs.

\section{Atividades turísticas em ambientes de alta biodiversidade e inclusão de comunidades locais.}

O turismo é uma atividade que avança no mundo todo. As informações mais recentes mostram que em 8 anos consecutivos houve um crescimento de $4 \%$ ao ano, sendo considerado acima da média. A partir do ano 2000, o aumento da atividade turística no Brasil e no Mundo foi significativo, sendo registrado entre 2003 a 2013 um crescimento de todas as categorias de turismo da ordem de $400 \%$ (WTO, 2018; MINISTÉRIO DO TURISMO, 2015).

O turismo de natureza, ou Ecoturismo é definido pela Sociedade Internacional de Ecoturismo como uma "viagem responsável a áreas naturais que conserva o meio ambiente, sustenta o bem-estar da população local e envolve interpretação e educação" (THE INTERNATIONAL ECOTOURISM SOCIETY-TIES, 2015). Segundo Kinker (2002), para que o turismo desenvolvido na natureza possa ser conceituado como ecoturismo, são necessárias: a conservação do ambiente visitado; a conscientização ambiental, tanto do turista como da comunidade receptora; e o desenvolvimento local e regional integrados.

Diegues (2001) e Bruhns (2005), discorrem sobre como a visão imposta pelo neomito da natureza intocada, como um paraíso perdido das áreas naturais sem intervenção humana, revela a realidade contraditória da proteção da natureza como necessidade fundamental para a reprodução dos modos de vida tradicionais. A idealização de ambientes selvagens, sem população, que precisam de proteção contra o homem "devastador/invasor", segundo Diegues (2001), não se justifica, uma vez que as comunidades tradicionais, na realidade, ocupam esses espaços e manejam os recursos naturais há muitas gerações, antes mesmo da criação do conceito e da legislação sobre áreas protegidas.

Um bom e pioneiro exemplo de turismo de natureza no Brasil é a Reserva de Desenvolvimento Sustentável Mamirauá (RDSM). Na RDSM turistas e população local tem acesso as informações advindas de pesquisas científicas e interagem com as mesmas como, por exemplo, no Projeto de Pesquisa de Botos da RDSM, onde turistas participam da pesquisa de campo e assistem uma palestra sobre todo o trabalho realizado (Peralta, 2002). Outro exemplo é a possibilidade dos turistas acompanharem a pesca manejada em lagos da reserva estabelecida em 1998 pelo PM da UC e comprarem pescado certificado advindo do manejo de pesca local do Pirarucu (Arapaima gigas) que fazem as comunidades da RDSM (INSTITUTO MAMIRAUÁ, 2019).

As RDSs podem ser consideradas áreas protegidas com elevado potencial para o ecoturismo. As populações locais que vivem nas RDSs podem ser inseridas no planejamento da atividade de diversas formas como, por exemplo, apresentando 
seu patrimônio natural e cultural aos turistas, e oferecendo um leque de mercadorias locais (produtos agrícolas, pesqueiros ou artesanato), visando aumentar a renda destas populações o que constitui o elemento 'turístico' do conceito. De acordo com alguns estudiosos, neste caso, a proposta de ecoturismo pode ser categorizada como turismo de base comunitária (TBC), pois além de contribuir para a conservação do ambiente, preza pelo desenvolvimento local, trazendo benefícios econômicos, sociais e culturais para os membros da comunidade (INSTITUTO ECOBRASIL, 2010).

O TBC não representa apenas um segmento de atividade turística como o turismo rural, turismo étnico ou mesmo o ecoturismo, mas sim uma proposta de turismo apoiado em bases endógenas e focado no desenvolvimento local (FABRINHO, 2012). Neste sentido, Sancho e Malta (2015) acredita que cada vez mais uma parcela da demanda turística optará por vivenciar múltiplas experiências relacionadas a atividade, não se encaixando em um único padrão ou segmento de mercado turístico, como, por exemplo, o cultural, o rural, o ecológico, mas também a compreensão do modo de vida das comunidades visitadas.

O TBC aparece como uma ferramenta para o desenvolvimento local, respeitando as heranças culturais e étnicas e fortalecendo a diversidade socioambiental das comunidades locais (THE MOUNTAIN INSTITUTE, 2000), representando o que Sancho e Malta (2015) identificam como uma contraposição ao turismo convencional de experiências padronizadas e superficiais notadamente dominado por empreendedores externos.

De acordo com estudo recente de Ferreira e Raimundo (2016), na RDSBU, ainda que sem ordenamento adequado, existem relações entre os moradores locais e os turistas, seja em pousadas ou campings, ou no desenvolvimento de atividades como a pesca artesanal ou esportiva, em monitorias, nas recepções a grupos de escolares e de universidade, representando experiências de sociabilidade, onde a vida comunitária e seus aspectos sociais, econômicos e culturais estão associados.

Com a proposta de ser uma alternativa de fonte de renda sustentável e de desenvolvimento local que concilie os objetivos da RDS com a permanência dos moradores locais na Vila da Barra do Una este trabalho se propôs analisar o potencial turístico da RDSBU, através da investigação das demandas, expectativas e do Conhecimento Ecológico Local da comunidade, relacionadas aos atrativos naturais existentes na RDS. Desta forma, as análises apresentadas a seguir poderão servir de subsídios para o futuro planejamento do TBC na RDSBU, resultando em roteiros efetivamente inclusivos, executados e monitorados pela própria comunidade que fomentem o pertencimento comunitário e incrementem a geração de renda na economia atual.

\section{Metodologia}

\section{Área de estudo}

Esta pesquisa foi desenvolvida nos anos de 2013 e 2014 na comunidade caiçara da Reserva de Desenvolvimento Sustentável da Barra do Una (RDSBU) no Município de Peruíbe e Iguape, localizada no sudeste do estado de São Paulo, inserida no Mosaico de Unidades de Conservação Juréia-Itatins (MUCJI) (Figura 1). 


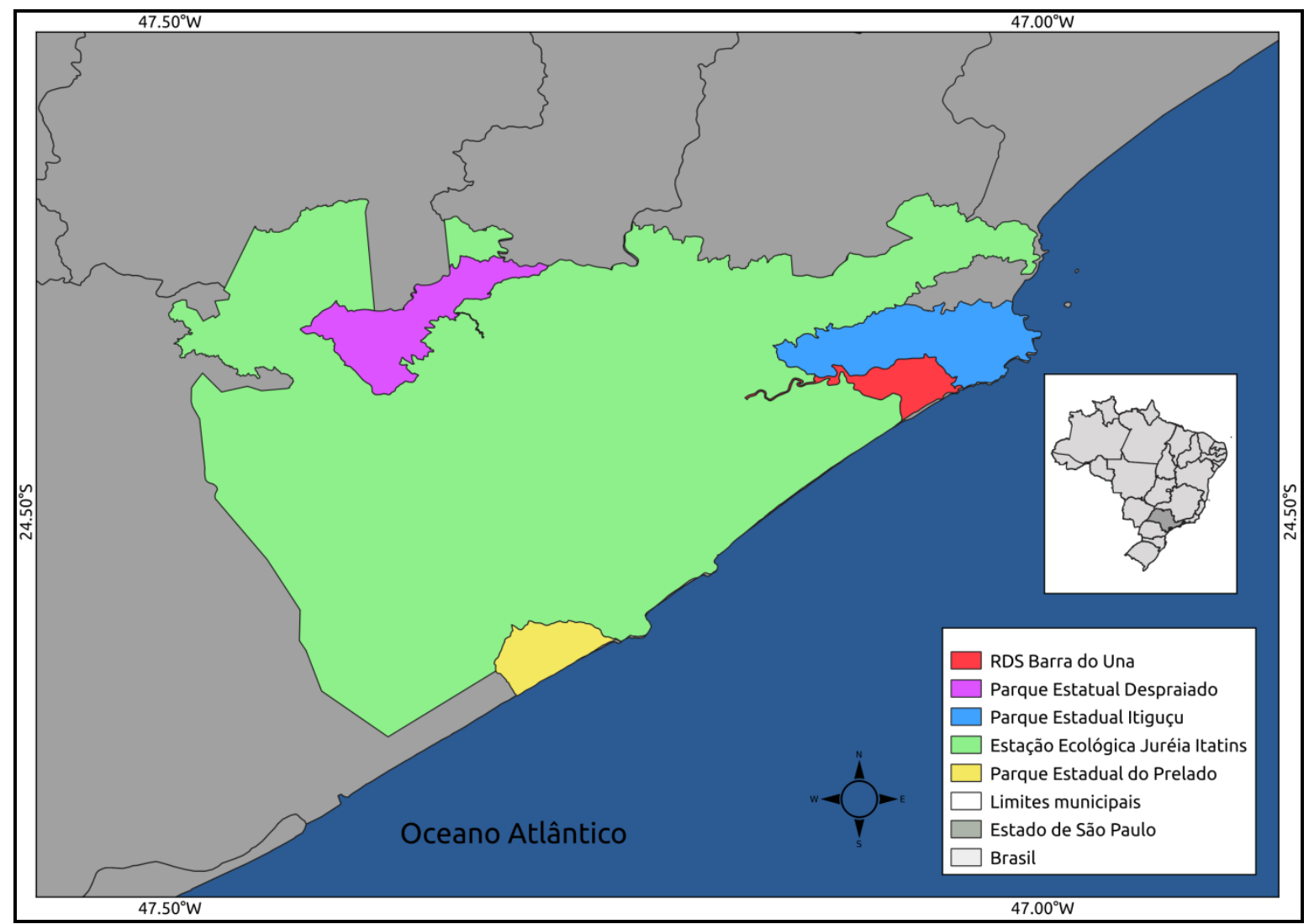

Figura 1: Localização da área de estudo: Reserva de Desenvolvimento Sustentável da Barra do Una (em vermelho) inserida no Mosaico de Unidades de Conservação Jureia-Itatins (colorido), São Paulo.

Figure 1: Study area location: Barra do Una Sustainable Development Reserve (in red) insert in the Jureia-Itatins Conservation Units Mosaic (colorful), São Paulo

Fonte: Elaborado pelos autores (2019).

Source: Prepared by the authors (2019).

O MUCJI foi instituído pela Lei 14982/13, e soma uma área total de 97.213 hectares. É composto por 6 categorias de UC diferentes, sendo quatro unidades de proteção integral: a EEJI, os Parques Estaduais de Itinguçu e Prelado, o Refúgio Estadual de Vida Silvestre das Ilhas do Abrigo e Guararitama e duas unidades de uso sustentável: a RDS Barra do Una e a RDS do Despraiado. Entre os objetivos do mosaico estão a preservação da natureza e a sustentabilidades das comunidades das reservas sustentáveis, bem como, o desenvolvimento da pesquisa científica e do ecoturismo (FUNDAÇÃO FLORESTAL, 2012).

A RDSBU foi criada pela Lei 14982 de 2013, e é formada pela Vila da Barra do Una, situada no município de Peruíbe, e parte do Rio Una no município de Iguape, totalizando 1.487 hectares do estado de São Paulo geridos pela Fundação Florestal do estado de São Paulo (FF-SP). Informações disponibilizadas pela FF-SP, identificam que cerca de 49 famílias vivem na RDSBU e a população total é composta por $54,5 \%$ homens e $45,5 \%$ mulheres. A maioria dos adultos e idosos estudaram no máximo até a quarta série do Ensino Fundamental, mas atualmente na vila as crianças frequentam a escola local e os jovens estudam na cidade vizinha de Peruíbe. A origem dos moradores é na maioria, advinda das áreas que atualmente compõem o MUCJI como o Rio Verde, Praia do Una, Rio Comprido, Barreirinho, Barra do Una, Caramborê, entre outras; alguns moradores nasceram em municípios ao longo do litoral do Brasil e chegaram na região ou por laços familiares, ou na época em que a região do Vale do Ribeira, SP fazia parte dos grandes ciclos 
econômicos do açúcar, café, etc. Estima-se que 47\% dos chefes de famílias da RDSBU vivem há mais de 24 anos nesta região, desde antes da criação da primeira área protegida da região, a Estação Ecológica Jureia-Itatins (FUNDAÇÃO FLORESTAL, 2012).

O acesso para a RDSBU se dá por meio de embarcações, pelo mar ou pelo Rio Una, ou pela estrada do Una, via de terra responsável pelo principal acesso à vila, cerca de $25 \mathrm{~km}$ e 1:30 hs da cidade de Peruíbe. Nessa estrada circula uma única linha de ônibus Estação/Peruíbe - Barra do Una, que se distribui em 4 diferentes horários ao longo do dia para o transporte dos visitantes e moradores (PEDROSA; CLAUZET, 2016). Não há atendimento médico efetivo na vila, havendo apenas um posto e um agente de saúde, o que obriga os moradores a buscar um atendimento mais qualificado na cidade vizinha de Peruíbe. A energia elétrica foi instalada no final dos anos 1980, entretanto, no geral, a vila ainda carece de iluminação nas ruas e melhor rede de comunicação digital (CAMILO, 2016). A água utilizada na vila é proveniente da cachoeira do Maceno aonde foi construído uma barragem para a sua captação (FERREIRA, 2015).

\section{Coleta de Dados}

O trabalho de campo foi planejado visando identificar se os moradores locais da RDSBU estão atentos a oportunidade que o turismo pode trazer em termos econômicos para suas vidas. Ao mesmo tempo, buscou-se diagnosticar os aspectos positivos ou que oportunizamos a existência de atividades turísticas na RDSBU, e os aspectos negativos, os limitantes ao desenvolvimento do TBC na região. Para a coleta de dados foram realizadas entrevistas com o auxílio de um questionário semiestruturado, sobre a infraestrutura da Vila e o potencial do turismo na RDSBU. De acordo com Albuquerque, Lucena e Cunha (2010), o questionário semiestruturado consiste em perguntas que apresentam grande flexibilidade e permitem aprofundar elementos que podem ir surgindo durante a entrevista.

Foram entrevistados moradores maiores de 18 anos e residentes na região por no mínimo dez anos. Utilizamos de tais critérios, pois assim consideramos que os entrevistados têm vivência e conhecimento detalhado do seu ambiente, o que potencializa sua participação na pesquisa e no alcance do nosso objetivo relacionado a investigar o potencial do TBC na RDSBU.

O esforço amostral foi definido pelo método "bola de neve" (BIERNACKI; WALDORF, 1981), onde cada morador entrevistado indicou outro morador ao final de sua entrevista, e assim sucessivamente, até que pudéssemos entrevistar o maior número de moradores locais indicados durante o trabalho de campo. Este método foi anteriormente utilizado com sucesso em diversos trabalhos de Ecologia Humana aplicados a comunidades caiçaras litorâneas e ribeirinhas amazônicas (BEGOSSI et al., 2011; FERREIRA et al., 2014; RAMIRES et al., 2015). Na coleta de campo não tivemos nenhum impedimento para encontrar os moradores indicados e ninguém se recusou a conceder entrevista. Vale destacar que o território da RDSBU é extenso e alguns locais indicados nas entrevistas não puderam ser visitados em campo para inclusão na discussão dos resultados, seja pela distância e dificuldade de acesso, seja por estarem dentro de área protegida restritiva e, portanto, não interessava para os objetivos da pesquisa visitá-los neste momento. 
Os dados foram analisados qualitativamente e quantitativamente buscando-se representar as divergências e o consenso entre as respostas dadas pelos informantes. Nesta abordagem, os aspectos (ou respostas) mais mencionados são considerados como informações mais relevantes do conhecimento ecológico local sobre o tema abordado (PAZ; BEGOSSI, 1996; SILVANO; MC CORD; LIMA; BEGOSSI 2006).

\section{Resultados e Discussão}

Foram entrevistados 25 moradores de ambos os gêneros, com idade média de 47 anos, dos quais $36 \%$ tem a pesca e $20 \%$ o comércio como principal fonte de renda. A maior parte dos entrevistados (72\%) desenvolvem alguma atividade relacionada ao turismo como, por exemplo, aluguel de casas na alta temporada e pequenos comércios e $32 \%$ desenvolvem atividades relacionadas ao ecoturismo, sendo que a principal atividade desenvolvida é a de monitoria aos atrativos naturais, como por exemplo praias, rios e cachoeiras. Ferreira (2019), encontrou pescadores artesanais residentes na RDSBU envolvidos na atividade turística de pesca esportiva, especificamente eles trabalham como piloteiros de embarcações utilizadas na pesca esportiva, e também no comércio de iscas vivas, guia de pesca e aluguel de barco e motor.

Sobre a alteração do status da Barra do Una de uma UC restritiva como a Estação Ecológica para uma categoria de uso sustentável como a RDS, 92\% dos moradores entrevistados apoiam a mudança, manifestando a satisfação dos moradores no direito de permanecer no território, possibilitando o desenvolvimento tanto as atividades tradicionais, como a pesca, quanto com as novas opções de fonte de renda, como por exemplo o turismo. Dos entrevistados, $52 \%$ gostariam de desenvolver apenas atividades turísticas como fonte de renda, demonstrando acreditar no potencial econômico vindo delas. Masud et al., (2017) observaram que os benefícios econômicos inspiram as comunidades a participar de práticas ecoturísticas; neste sentido, o interesse em desenvolver o turismo demonstrado pelos moradores da RDSBU é um primeiro passo decisivo para que o TBC possa ser planejado como atividade socioeconômica local. Irving (2009) comenta que a motivação e o desejo de comunidades locais em desenvolver atividades ligadas ao TBC, são vitais para o seu sucesso, sem esses elementos, dificilmente atenderá as demandas de desenvolvimento local e de protagonismo social.

Ferreira (2014) destacou anteriormente num estudo de caso na praia do Aventureiro, em llha Grande, RJ, a importância que o TBC tem na garantia do território comunitário associado as RDSs. O desafio da integração e coesão entre comunitários, gestores e turistas apresentado no planejamento de TBC favorece a organização social e representatividade local, que por sua vez, fortalece a institucionalização e o desenvolvimento contínuo da própria RDS como uma área protegida de uso sustentável. Somado a isto, o turismo desenvolvido com inclusão das comunidades pode contribuir para reduzir a pressão sobre os recursos naturais como por exemplo, os recursos pesqueiros, no caso de comunidades que vivem somente da pesca (LOPES et al., 2011).

Segundo $56 \%$ dos entrevistados o principal benefício que o TBC pode trazer é "mais uma fonte de renda". Essa expectativa é compreensível, uma vez que hoje o turismo local, ainda sem planejamento, já representa uma importante fonte de renda local através de alugueis de casas, pequenos comércios, além do turismo de pesca 
esportiva (FERREIRA; RAIMUNDO, 2016; FERREIRA, 2019). Entretanto, no âmbito internacional, Zapata (2011) verificou que em comunidades pobres da nicarágua, mesmo com a ênfase sobre o TBC como indutor de desenvolvimento, o mesmo teve pouco impacto em relação a trabalho e renda nos locais estudados, destacando que a pequena escala dos empreendimentos e a falta de habilidade das comunidades em tornar o negócio economicamente viável, são as principais causas do fracasso da inciativa local.

Neste contexto, a literatura mostra que a sustentabilidade das iniciativas de TBC propostas, dependem da motivação por parte dos grupos sociais locais, e do protagonismo social nas tomadas de decisão que devem superar as lacunas recorrentes nos processos de planejamento turístico no Brasil, em que os comunitários no geral não participam, e se estão integrados, não têm poder decisório (IRVING, 2009; PINHEIRO, 2014; ALMEIDA; CASTRO, 2017).

Os entrevistados foram questionados sobre o que deve ser melhorado na Vila da Barra do Una, para que a recepção ao turista seja bem realizada, indicando a necessidade de aspectos de infraestrutura e direitos básicos dos cidadãos serem implementados e/ou melhorados na região (Figura 2).

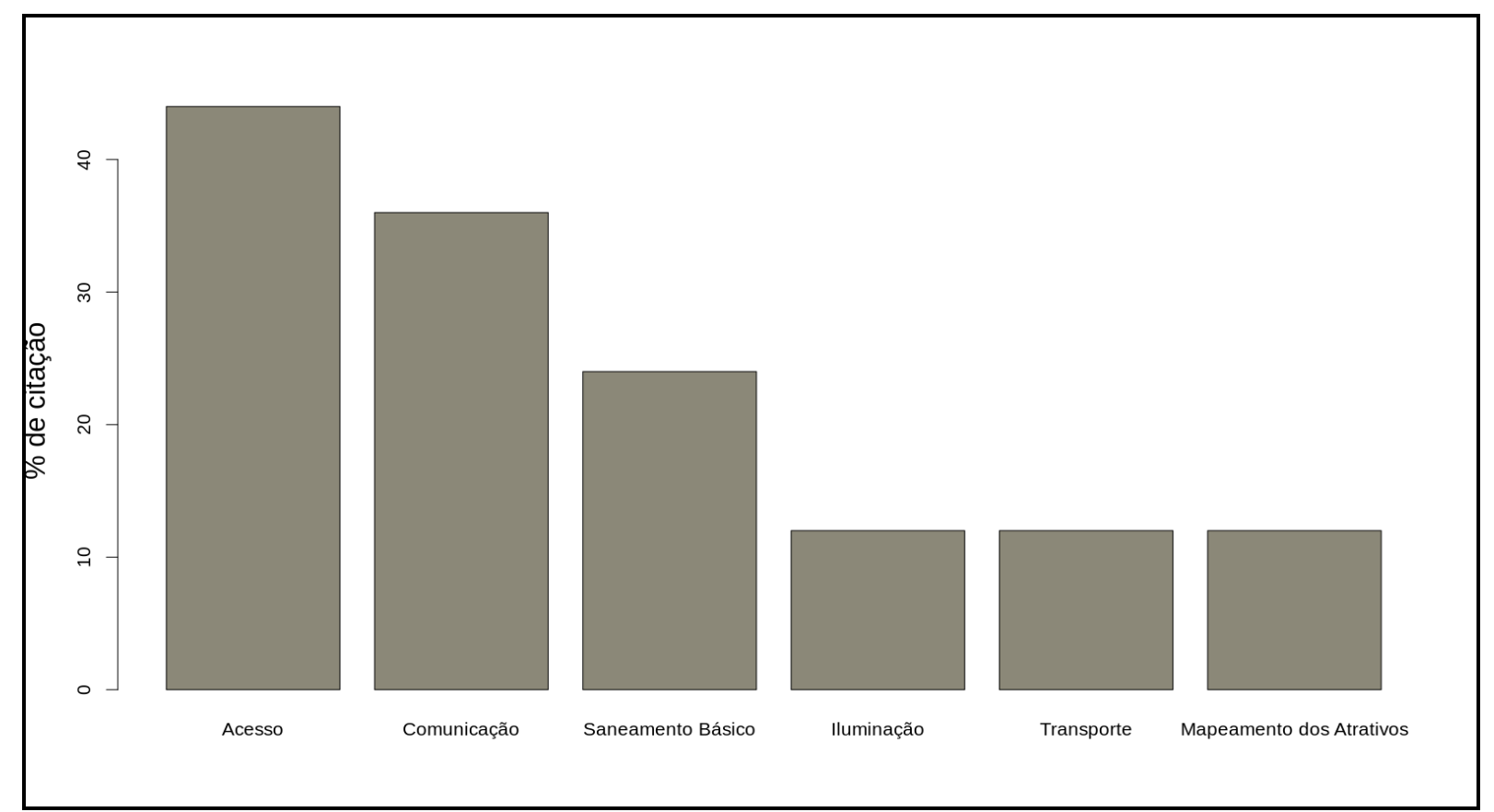

Figura 2: Melhorias de infraestrutura necessárias para o receptivo turístico segundo moradores da $\operatorname{RDSBU}(\mathrm{n}=25)$.

Figure 2: Infrastructure improvements needed for the tourist reception according BUSDR residentes. $(n=25)$.

Os itens que foram mais citados como aspectos a serem melhorados foram: 0 "Acesso à Vila" (44\%), em seguida, a "lluminação" e os "Meios de Comunicação" (somando 36\%, 24\%, respectivamente). Os itens "Acesso à Vila" e Transporte Público (12\%) foram anteriormente registrado por Pedrosa e Clauzet (2016) como grande problema da comunidade, que tem poucas linhas e horários de ônibus, além do fato de muitas vezes o acesso pela estrada de terra ser interrompido devido as condições climáticas impedindo os usuários de se deslocaraem. 
Sobre os meios de comunicação, citado por $24 \%$ dos entrevistados, vale destacar que nos anos de 2013/2014 quando o trabalho de campo foi realizado, não havia internet e nem sinal celular na vila, havendo somente dois telefones públicos, que frequentemente encontram-se fora de funcionamento. Atualmente a internet está instalada, mas sem acesso ainda a telefonia móvel, contudo efetivamente a comunicação da rede de internet é precária. A insatisfação dos moradores da RDSBU com este aspecto, foi retratada recentemente por Camilo (2016) indicando que, mesmo depois da possibilidade de instalação de rede de internet, o uso ainda é insuficiente.

Ferreira (2015) ressalta o impacto negativo da ausência de um bom sistema de conexão via celular e internet no turismo da RDSBU, podendo influenciar na permanência dos turistas além da estadia programada, uma vez que teriam outra opção de pagamento através de serviços de cartões, podendo cobrir valores de hospedagem e alimentação, além da possibilidade de ficar conectados com seus familiares e cumprir suas responsabilidades profissionais à distância. Camilo et al., (2015) atentam para o potencial efeito positivo na comunidade com a criação, por exemplo, de uma plataforma digital que comunicasse os moradores, os visitantes, a imprensa, os cientistas e as instituições relacionadas às causas ambientais do MUCJI, aliando divulgação à conservação da cultura e biodiversidade local.

Neste contexto, a problemática da ausência de divulgação dos pontos turísticos da comunidade, relatada por $12 \%$ dos entrevistados seria solucionada, incluindo na plataforma digital alguns mapas, fotos e descrições dos atrativos aos potenciais turistas interessados.

O difícil acesso à Barra do Una entendido por $44 \%$ como problema, somado a ausência de efetiva comunicação são atributos que evidenciam a carência da comunidade em aspectos básicos fundamentais para a qualidade de vida e necessários para o desenvolvimento do turismo no local. Ferreira (2019) em seu estudo na RDSBU, observou que muitos moradores reconhecem um aumento da demanda da pesca esportiva, mas dependente das condições da estrada, sendo junto com o ordenamento do turismo, as demandas dos moradores locais para que 0 turismo possa desenvolver na RDS

Diversos itens de infraestrutura são utilizados como indicativos de sustentabilidade turística elaborado pela Organização Mundial do Turismo-OMT (PINHEIRO, 2014), e a literatura destaca que a infraestrutura física é um dos catalisadores básicos do desenvolvimento do turismo e do ecoturismo, uma vez que determina a atração, a acessibilidade e a permanência das pessoas no local de destino turístico (GUNN, 2002; RAY et al., 2015; BEKELE et al., 2017).

Foram indicados pela comunidade 14 atrativos com potencial turístico, dos quais 7 com maiores frequências de citações (Figura 3). 


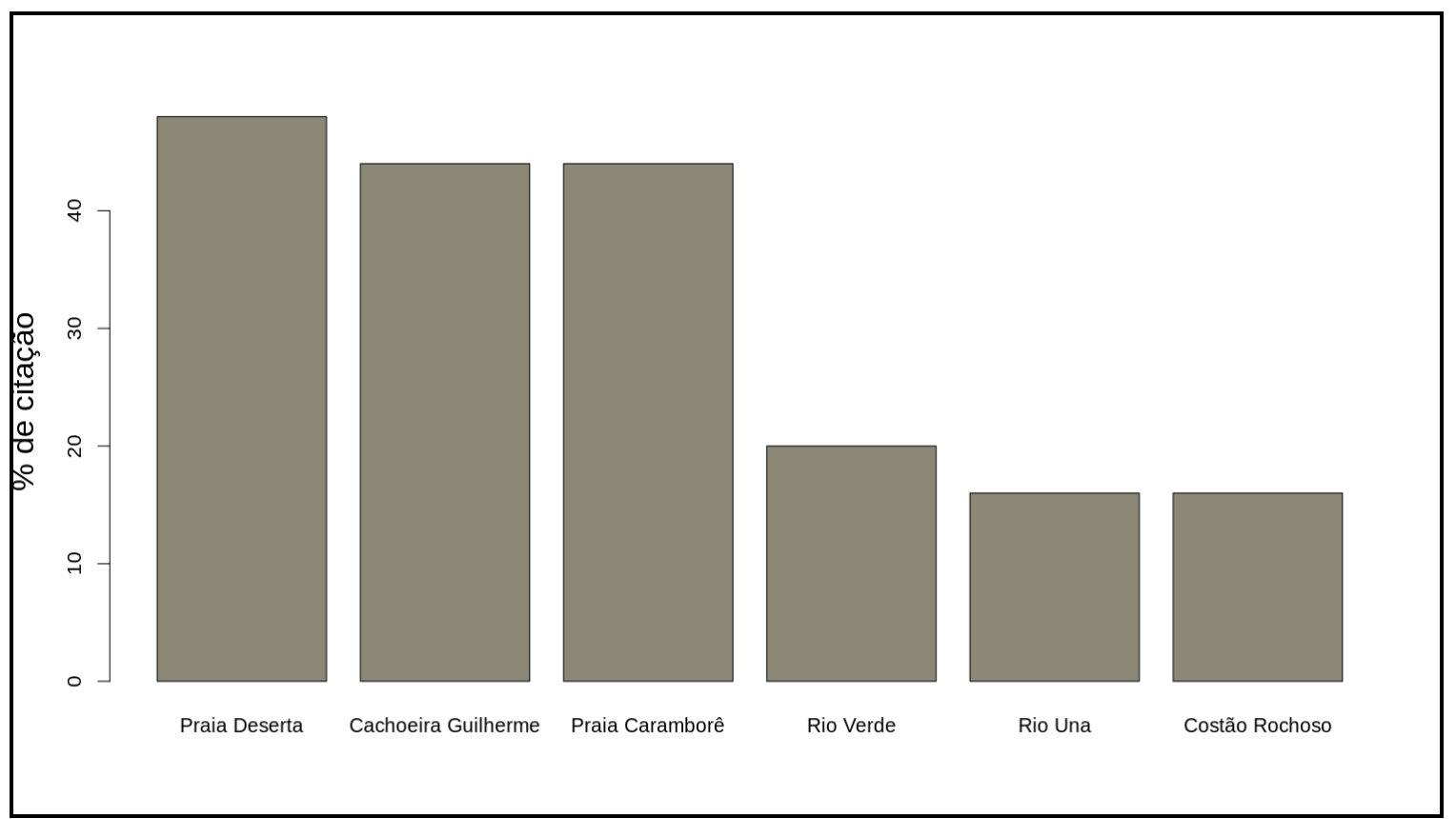

Figura 3: Locais de potencial turístico segundo moradores da RDSBU. $(n=25)$.

Figure 3: Places with local tourist potential, according to BUSDR residents $(n=25)$.

Dois dos locais mais citados, a Cachoeira do Guilherme (44\%) e o Rio Verde (20\%) estão inseridos na área da Estação Ecológica, na qual não é permitida a utilização a visitação para turistas, sendo uma categoria de UC destinada apenas para fins científicos, com autorização do órgão gestor e acompanhamento de monitoria oficial. Neste caso, se considerarmos a expressiva \% de citações para tais localidades (Cachoeira do Guilherme 44\% e Rio Verde 20\%), geralmente acompanhadas de expressões de encantamento sobre a beleza natural a que estão inseridas, pode-se considerar que a categoria de UC restritiva EE está impactando negativamente o potencial de desenvolvimento da atividade turística na RDSBU, pois são localidades entendidas pelos moradores como locais de elevado potencial turístico para a RDS.

Autores como Berkes e Folke (1998), Adams (2000), Diegues e Arruda (2001), Lopes et al., (2015), entre outros, argumentam que muitas áreas consideradas "prioritárias para conservação", estão com índices de biodiversidade exemplares, que chamam a atenção para a conservação dos recursos naturais locais e se tornam ambiente propícios para pesquisas científicas, decorrentes justamente do manejo dos recursos naturais que as populações usuárias mantiveram com o ambiente durante gerações e que, portanto, os processos de implementação das diversas categorias de UC's de uso restritivo não podem ser impostos em processos "top-down", mas sim, definidos em acordo com a categoria de UC que melhor represente a realidade de cada localidade, garantindo assim, 0 comprometimento dos usuários e o alcance dos objetivos de conservação em UCs.

Outro local citado a Cachoeira do Paraíso (8\%) está incluído na área do Parque Estadual do Intiguçu. Por se tratar de uma área de Parque Estadual, 0 turismo é permitido e ocorre de maneira ordenada, onde o acesso é controlado por senha retirada no portal de acesso da Estação Ecológica Juréia Itatins (230 senhas por dia), diminuindo o potencial impacto negativo causado pelos turistas no atrativo. Mesmo com poucas citações (8\%), é provável que esse local tenha sido indicado por já ser utilizado como roteiro turístico regional. 
Dentre os potenciais pontos turísticos citados, quatro deles estão localizados em áreas dentro do limite da RDSBU: a Praia da Deserta (48\%), Praia do Caramborê (45\%), Costão Rochoso e Rio Una (16\% cada), os quais por estarem já inseridos dentro da RDSBU poderiam ter o ordenamento e início das atividades facilitado. Com objetivo de contribuir para o planejamento do turismo, os locais citados pelos moradores foram caracterizados em caráter preliminar através de incursões, que buscaram identificar a logística e infraestrutura de acesso, aspectos ambientais, o potencial de público visitante e algumas sugestões de uso que estão indicadas na tabela a seguir (Tabela1).

Tabela 1: Caracterização e sugestões de usos dos principais locais com potencial turístico, citados na RDSBU.

Table 1: Characterization and uses suggestions of the BUSDR main places mentioned as having tourist potential.

\begin{tabular}{|c|c|c|c|c|}
\hline $\mathbf{s}$ & $\begin{array}{l}\text { Prala da veserta } \\
(48 \%)\end{array}$ & $\begin{array}{l}\text { Praia do } \\
\text { Caramborê }(45 \%)\end{array}$ & Rio Una (16\%) & 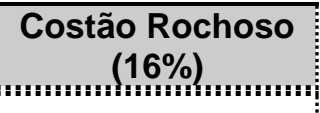 \\
\hline $\begin{array}{l}\text { Presença de } \\
\text { Moradores }\end{array}$ & Não & Sim & Não & Não \\
\hline Form & $\begin{array}{c}\text { Trilha ou } \\
\text { embarcação }\end{array}$ & $\begin{array}{c}\text { Trilha ou } \\
\text { embarcação }\end{array}$ & $\mathrm{pr}$ & pr \\
\hline Estin & $2,4 \mathrm{Km}$ & $1,5 \mathrm{Km}$ & & 60 \\
\hline Tipo de Vegetação & $\begin{array}{l}\text { Inicia-se por } \\
\text { Restinga até } \\
\text { Floresta Ombrófila } \\
\text { Densa }\end{array}$ & $\begin{array}{l}\text { Inicia-se por } \\
\text { Restinga até } \\
\text { Floresta Ombrófila } \\
\text { Densa }\end{array}$ & $\begin{array}{l}\text { Resti } \\
\text { Mang }\end{array}$ & $\begin{array}{l}\text { Bromélias e } \\
\text { Cactáceas }\end{array}$ \\
\hline Público Suge & $\begin{array}{l}\text { Adultos, Crianças, } \\
\text { Escolas, } \\
\text { Universidades e } \\
\text { Grupos de } \\
\text { Pesquisa }\end{array}$ & $\begin{array}{l}\text { Adultos, Crianças, } \\
\text { Escolas, } \\
\text { Universidades e } \\
\text { Grupos de } \\
\text { Pesquisa }\end{array}$ & $\begin{array}{l}\text { Adultos, Crianças, } \\
\text { Escolas, } \\
\text { Universidades e } \\
\text { Grupos de } \\
\text { Pesquisa }\end{array}$ & $\begin{array}{c}\text { Adultos, Crianças, } \\
\text { Escolas, } \\
\text { Universidades e } \\
\text { Grupos de } \\
\text { Pesquisa }\end{array}$ \\
\hline $\begin{array}{l}\text { Potenciais } \\
\text { atividades e } \\
\text { empregos }\end{array}$ & $\begin{array}{l}\text { Guias locais para o } \\
\text { trajeto; } \\
\text { Pontos de apoio ao } \\
\text { turista }\end{array}$ & $\begin{array}{l}\text { Guias locais para } \\
\text { trilha; Aluguéis de } \\
\text { embarcações } \\
\text { locais para trajeto } \\
\text { pelo mar; } \\
\text { Pontos de apoio ao } \\
\text { turista }\end{array}$ & $\begin{array}{c}\text { Guias locais; } \\
\text { atividades de } \\
\text { pesca esportiva; } \\
\text { Aluguéis de } \\
\text { embarcações para } \\
\text { passeio no Estuário }\end{array}$ & $\begin{array}{l}\text { Escaladas, } \\
\text { observação } \\
\text { paisagística. }\end{array}$ \\
\hline
\end{tabular}

Vale destacar que três dos pontos citados são locais sem presença de moradores, bastante preservados em sua beleza natural, o que pode maximizar a sensibilização dos turistas à natureza e à importância da manutenção da conservação do destino visitado. Os potenciais roteiros turísticos às praias do Caramborê e Deserta podem incluir viagens de barco, empregando, além do morador local como monitor (ou guia) ambiental, outros moradores locais na função de pilotos destas embarcações e/ou guias de pesca esportiva. A pesca esportiva na RDSBU vem sendo estudada pelo grupo do Laboratório de Ecologia Humana da Universidade Santa Cecília, liderado pela Profa. Dra. Milena Ramires, no âmbito do Projeto Etnoecologia e Conservação de Robalos no Mosaico de Unidades de Conservação Jureia-Itatins (CNPq - processo o 420144/2016-1), através do qual parte dos resultados apontam tanto para um largo conhecimento ecológico local passível de ser aplicado na pesca esportiva (BARRELLA et al.; 2016; SILVA, 2016), quanto para o potencial de crescimento da pesca esportiva na RDSBU, que 
atualmente já é realizada por 27 moradores locais indicando a necessidade de ser planejada e ter seu ordenamento incluído no PM (FERREIRA, 2019).

Nossos resultados apontam para o potencial de inclusão nos roteiros de TBC o grande manguezal que fica às margens do Rio Una, citado como potencial ponto turístico por $16 \%$ dos entrevistados. Como se sabe, os manguezais são considerados um dos ecossistemas mais produtivos do mundo, conhecidos como o berçário do ambiente marinho é um importante habitat para alimentação, proteção e reprodução de muitas espécies dulcícolas, marinhas e estuarinas e permitem a sobrevivência de inúmeras comunidades locais (ICMBio, 2015). Devido à sua importância econômica relacionada à grande variedade de bens e serviços prestados por este ecossistema à sociedade o governo brasileiro estabeleceu uma estratégia para a conservação e uso sustentável dos manguezais na forma do Plano de Ação Nacional para a Conservação das Espécies Ameaçadas e de Importância Socioeconômica do ecossistema Manguezal na costa Brasileira-PAN Manguezal através da Portaria no 9 de janeiro de 2015 (ICMBIO, 2015).

É importante enfatizar que o PAN-Manguezais incorpora em seus objetivos a possibilidade de execução de ações de uso deste ecossistema que promovam o desenvolvimento socioeconômico em regiões de manguezais habitadas como, por exemplo, a captura de Carangueijo-uça (Urcides cordatos) que foi localmente regulamentada pelo IBAMA (2015), uma vez que tal atividade faz parte do modo de vida tradicional na RDSBU. Além disto, no SNUC é destacada a importância das Diretrizes para a Estratégia Nacional de Comunicação e Educação Ambiental estarem incluídas nos PMs das UCs. Portanto, evidenvia o potencial da Vila da Barra do Una em desenvolver roteiros de Educação Ambiental relacionados a manguezais, focados não apenas em turistas, mas voltado também a visitação de alunos de escolas públicas, privadas das cidades próximas.

Por fim, mas não menos importante, vale destacar que o costão rochoso da Praia do Una, também indicado nas entrevistas, vem sendo utilizado para a prática de escalada por turistas adeptos de esportes radicais, ou turismo de aventura. Tal atividade pode ser executada com a inclusão dos moradores locais como monitores ou guias, contudo se faz urgente seu ordenamento para que este uso não impacte negativamente os costões e possa ser executado com normas de segurança para os visitantes.

\section{Conclusão}

A necessidade de revisão e recategorização de UCs no Estado de São Paulo é um tema muito evidente, e ainda recorrente, sendo marcado por muitas desapropriações e demolições de residências de populações tradicionais que habitam essas áreas muito antes dos decretos de criação e implementação de áreas protegidas, que quando implementadas podem impor certas regras de usos de recursos naturais que impedem a manutenção e reprodução dos modos de vida.

No caso analisado neste estudo, a alteração de status de UC Proteção Integral para uma UC de Uso Sustentável, trouxe para a Vila Barra do Una uma nova perspectiva de desenvolvimento, com maior número de potenciais atividades econômicas e menor restrição as atividades tradicionais relacionadas ao uso dos recursos naturais, como por exemplo, o cultivo de plantas para consumo e uso medicinal e a pesca estuarino-marinha. 
A Vila da Barra do Una se apresenta com um grande potencial em desenvolver atividades turísticas, com um rico histórico de relação íntima com ambiente, presente na cultura Caiçara, e com muitos atrativos naturais indicados pelos moradores, que se mostraram dispostos a se dedicarem a essas atividades, tendo no retorno financeiro um importante fator de motivação. Porém, para o pleno desenvolvimento do turismo, a Barra do Una necessita de melhorias básicas de infraestrutura, bem como a capacitação de moradores locais para atuar nas atividades.

O TBC aparece como uma potencial ferramenta para o desenvolvimento sustentável local, que se contrapõe ao modelo tradicional de turismo exploratório e degradante, que aparece apenas em benefício de populações urbanas. Demanda, contudo, um planejamento cuidadoso e interinstitucional para sua implementação, trazendo para os moradores a possibilidade e o desafio na busca de autonomia para a organização das demandas locais, e de representatividade comunitária na condução de processos de uso territorial, elementos essenciais para o desenvolvimento do TBC.

\section{Referências}

ALBUQUERQUE, U.P.; LUCENA, R.F.P.; CUNHA, L.V.F.C. Métodos e técnicas na pesquisa etnobiológica e etnoecológica. Recife - PE, NUPEEA. Volume 1. (Coleção estudos \& avanços). p.351 2010.

ADAMS, C. Caiçaras na Mata Atlântica: Pesquisa científica versus Planejamento e Gestão Ambiental. Annablume: FAPESP. p.336. 2000.

AGRAWAL, A. Common resources and institutional sustainability. In: OSTROM, E.; DIEZ, T.; DOLSACK, N.; STERN, P.C.; STONICH, S.; WEBER, U.E. (Eds.). The Drama of the Commons. National Academy Press: Washington, p. 41-86. 2001.

ALMEIDA, F. A. B.; CASTRO, J. F. Planejamento do turismo de base comunitária: perspectivas críticas. Caderno Virtual de Turismo, v. 17 n. 3, p.66-81. 2017

BEGOSSI, A.; SALIVONCHYK, S. V.; ARAUJO, L. G.; ANDREOLI, T. B.; CLAUZET, M.; MARTINELE, C. M.; FERREIRA, A.G.L.; OLIVEIRA, L.E.C.; SILVANO, R. A. M. Ethnobiology of snappers (Lutjanidae): target species and suggestions for management. Journal of Ethnobiology and Ethnomedicine, v. 7 n. 11. p.22. 2011.

BERKES, F.; FOLKE, C. Linking ecological and social systems for resilience and sustainability. In: Berkes, F; Folke, C; Colding, J. (eds.). Linking social and ecological systems: Management practices and social mechanisms for building resilience. Cambridge University Press. p.1-26. 1998.

BEKELE, H.; TESHOME, E.; ASTERAY, M. Assessing protected areas for ecoturism development: The case of Maze National Park, Ethiopia. Journal of Hospitality Management and Tourism, v. 8 n. 3, p. 25-31. 2017.

BIERNACKi, P.; WALDORF, D. Snowball sampling-problems and techniques of chain referral sampling. Sociological Methods and Research, v. 10 n. 2, p.141-163.1981 BRASIL. Sistema Nacional de Unidades de Conservação. Lei número 9.985, de 18 de julho de 2000.

BRUHNS H. T. O ecoturismo e o mito da natureza intocada. Acta Scientiarum Human and Social Sciences, 32, (2), p.157-164. 2005. 
CAMILO, S.; BARRELLA, W.; RAMIRES, M. Projeto de portal integrado a redes sociais, para o Mosaico de Unidades de Conservação Jureia-Itatins (SP). Anais do 4ํㅡㄹ Encontro Nacional de Pós-graduação/ Universidade Santa Cecília (Unisanta), Santos SP, Brasil. p. 594. 2015.

CAMILO, S. O uso potencial da comunicação para conservação da Reserva de Desenvolvimento Sustentável Barra do Una, Peruíbe (SP). Dissertação (Mestrado) Universidade Santa Cecília, Programa de Pós-Graduação em Sustentabilidade de Ecossistemas Costeiros e Marinhos, Santos, SP. p.77. 2016.

CARLSSON, L.; BERKES, F. Co-management: concepts and methodological implications. Journal of Environmental Management, v. 75, p.65-76. 2005.

DIEGUES, A. C. S. Pesca e marginalização no litoral paulista. Dissertação (Mestrado). Departamento de Ciências Sociais. Universidade de São Paulo. USP. São Paulo, SP. p.184. 1973.

DIEGUES, A. C. S. Diversidade Biológica e Culturas Tradicionais Litorâneas: O Caso das Comunidades Caiçaras. NUPAUB-USP. IV Conferência da IUCN. São José, Costa Rica. p.37 1988.

DIEGUES, A. C. S. O mito moderno da natureza intocada / Antonio Carlos Santana Diegues. 3. ${ }^{a}$ ed. São Paulo: Hucitec Núcleo de Apoio à Pesquisa sobre Populações Humanas e Áreas Úmidas Brasileiras, USP. p. 161. 2001.

DIEGUES, A.C.S.; ARRUDA, R.S.V. Biodiversidade e comunidades tradicionais no Brasil no contexto da Convenção sobre Biodiversidade Biológica. Ministério do Meio Ambiente; COBIO (CNPQ) e NUPAUB - USP. 2001.

FABRINHO, N.H.; COSTA, H.A. Nascimento, E.P. Turismo de Base Comunitária (TBC): elementos chaves para aferir seu desempenho na perspectiva da sustentabilidade. Revista Brasileira de Ecoturismo, v. 5 n. 3, p. 546-559. 2012.

FERREIRA, H. M.; REUSS-STRENZE, G. M., ALVES, J.A.; SCHIAVETTi, A. Local ecological knowledge of the artisanalfishers on Epinephelus itajara (Lichtenstein, 1822) (Teleostei: Epinephelidae) on Ilhéus coast - Bahia State, Brazil. Journal of Ethnobiology and Ethnomedicine. 2014.

FERREIRA, H.C.H. Turismo Comunitário, Tradicionalidade e Reserva de Desenvolvimento Sustentável na Defesa do Território Nativo: Aventureiro-Ilha Grande/RJ. Revista Brasileira de Pesquisa em Turismo, 8 (2), p. 361-379. 2014.

FERREIRA, L.R.P. Contribuição do conhecimento local para o ordenamento da pesca esportiva e conservação de robalos na Reserva de Desenvolvimento Sustentável da Barra do Una, Peruíbe/SP. 2019. 66 f. Dissertação (Mestrado em Sustentabilidade de Ecossistemas Costeiros e Marinhos. Universidade Santa Cecília, Santos, 2019.

FERREIRA, P.T.A. Do Passado que insiste em persistir: Conflitos e possibilidades para um desenvolvimento do turismo de base comunitária na Vila Barra do Una Em Peruíbe (SP). 2015. 199 f. Dissertação (Mestrado em Mudança Social e Participação Política). Universidade de São Paulo, USP. São Paulo, 2015

FERREIRA, P.T.A.; RAIMUNDO, S. Conflitos e possibilidades para um desenvolvimento do turismo de base comunitária na Vila de Barra do Una em Peruíbe (SP). Caderno Virtual de Turismo, v. 16, n. 2, p. 150-167. 2016. 
FUNDAÇÃO FLORESTAL. Estudo técnico para recategorização de Unidades de Conservação e Criação do Mosaico de UC's Jureia-Itatins. Secretaria de Meio do Governo do Estado de São Paulo. p. 187. 2012.

GUNN C. Tourism planning - Basics, concepts, cases. Ed New York: Taylor \& Francis Books. p.464, 2002.

IBAMA - Instituto Brasileiro do Meio Ambiente e Recursos Renováveis. Proposta Nacional de Gestão para uso sustentável do Caranguejo-uça, do Guaiamun e do Siri-azul. Ministério do Meio Ambiente - Diretoria de uso Sustentável da Biodiversidade e Florestas Coordenação-Geral de Autorização de uso e Gestão de Fauna e Recursos Pesqueiros, 2015, p. 156

ICMBio - INSTITUTO CHICO MENDES DE CONSERVAÇÃO DA BIODIVERSIDADE. Portaria no 09 de 29 de Janeiro de 2015. Aprova o Plano Nacional para Conservação das Espécies Ameaçadas e de Importância Socioeconômica do Ecossistema Manguezal - PAN Manguezal. Diário Oficial da União, Poder Execultivo, Brasília, DF, 30 de janeiro. Seção 01, p.140.

Instituto Ecobrasil. Turismo comunitário TBC, 2010 Disponível em: <http://www. ecobrasil.eco.br/turismo/turismo-comunitario>. Acessado em: 01 abril de 2019.

IRVING, M. Reinventando a reflexão sobre turismo de base comunitária. In: BARTHOLO, R.; SANSOLO, D.G., BURSZTYN, I. (Org.). Turismo de Base Comunitária: diversidade de olhares e experiências brasileiras. 1.ed. Rio de Janeiro: Ed. Letra e Imagem. 2009. p.108-119.

KINKER, S. Ecoturismo e a conservação da natureza em parques nacionais. Campinas- SP: Papirus, Edição 1. 224p. 2002.

LOPES, P.F.M.; SILVANO, R.A.M.; BEGOSSI, A. Extractive and Sustainable Development Reserves in Brazil: resilient alternatives to fisheries. Journal of Environmental Planning and Management, v. 54 n. 8, p.421-443. 2011.

LOPES, P.F.M.; ROSA, E. A. M.; SALYVONCHYK, S.; NORA, V.; BEGOSSI, A. Suggestions for fixing top-down coastal fisheries management through participatory approaches. Marine Policy, v. 40, p.100-110. 2013.

LOPES, P.; PACHECO, S; ClaUZET, M.; SILVANO, R. M. A.; BEgOSSi, A. Fisheries, tourism, and marine protected areas: Conflicting or synergistic interactions? Elsevier. Ecosystem Service,v. 16, p.333-340. 2015.

MASUD, M. M.; ALDAKHIL, A. M.; NASSANI, A. A.; AZAM, M. N. Community-based ecotourism management for sustainable development of marine protected areas in Malasyia. Ocean \& Costal Management, v. 136, p;104-112. 2017.

MCKEAN, M. A.; OSTRON, E. Regimes de propriedade comum em florestas: Somente uma relíquia do passado? . In: Diegues, A. C. S. \& Castro, A.M. (Org.). 2001. Espaços e recursos naturais de uso comum. 1.ed. São Paulo NUPAUB/LASTROP. P. 79-96

MOUNTAIN INSTITUTE. Community-Based Tourism for Conservation and Development: A Resource Kit. The Mountain Institute. 2000. Disponível em: http://mountain.org/publications. Acessado em: 04 Junho de 2014.

MINISTÉRIO DO TURISMO. (2015). Turismo no Brasil: 2011-2014. Disponível em: $<$ http://www.turismo.gov.br/sites/default/turismo/o ministerio/publicacoes/downloads publicacoes/Turismo no Brasil 2011 - 2014 sem margem corte.pdf $>$. Acessado em: 20 outubro de 2015. 
NUNES, M. Do passado ao futuro dos moradores tradicionais da EEJI. 2003 Dissertação (Mestrado em Geografia). Faculdade de Filosofia, Letras e Ciências Humanas, Universidade de São Paulo, São Paulo. 152p.

OSTROM, E. A General Framework for Analyzing Sustainability of Social-Ecological Systems. Science, v. 325 n. 5939, 419-422. 2009.

PAZ, V.; BEGOSSI, A. (1996). Ethnoichthyology of Gamboa Fishermen of SepetibaBay, Brazil. Journal of Ethnobiology, v. 16, n. 2, 157-168.

PEDROSA, R. A.; CLAUZEt, M. Estudo da percepção dos moradores locais sobre o transporte público na Reserva de Desenvolvimento Sustentável da Barra do Una (Peruíbe, SP). Unisanta Bioscience, v. 5, 94-102. 2016.

PERALTA, N.B. Implantação do Programa de Ecoturismo na Reserva de Desenvolvimento Sustentável Mamirauá, Amazonas, Brasil. OLAM - Ciências e Tecnologia. Rio Claro. Aleph, v. 2, n. 2, 169-193. 2002.

PINHEIRO, T. R. Indicadores para o Desenvolvimento Sustentável do Turismo de Base Comunitária: Um estudo de Caso da Comunidade do Quilombo do Campinho da Independência, Paraty, Rio de Janeiro. Anais Brasileiros de Estudos Turísticos, v. 4, n. 1, 61-71. 2014.

RAMIRES, M.; CLAUZEt, M.; BARRELLA, W.; ROTUNDO, M.M.; SILVANO, R A M.; BEGOSSI, A. Fishers knowledge about fish trophic interactions in the southeastern Brazilian coast. Journal of Ethnobiology and Ethnomedicine, v. 11 n. 19. 2015.

ROSA, F.P. "Nativo Mudo" e o contraponto da gestão participativa e do turismo de base comunitária na reserva de desenvolvimento sustentável barra do una Mosaico da Juréia - Itatins. 2007. Monografia (Graduação Turismo). Universidade Estadual de São Paulo, Rosana, SP. 2007.

SANCHO, A.; MALTA, G. Pesquisa de Demanda para Turismo de Base Comunitária: desafios à promoção do encontro entre comunidades e viajantes. Turismo em Análise, 6 (1), 38-67. 2015.

SANTOS, C. Z.; SCHIAVETTi, A. Assessment of the management in Brazilian Marine Extractive Reserves. Ocean \& Coastal Management, v. 93, p. 26-36. 2014.

SÃO PAULO. Diário Oficial Estado de São Paulo. Diário de Justiça Eletrônico Caderno Judicial - 2º Instância. São Paulo, Ano VII - Edição 1557. p 609, 610. Dezembro, 2013.

SÃO PAULO. Diário Oficial Estado de São Paulo. Diário de Justiça Eletrônico Caderno Judicial - 1ำ Instância - Interior - Parte II. São Paulo, Ano VII - Edição 1683. p 2246. Junho, 2014.

SILVA, L. G. S.; DIEGUES, A. C. S. Caiçaras jangadeiros: cultura marítima e modernização no Brasil. CEMAR- Centro de Culturas Marítimas. Universidade de São Paulo- USP, São Paulo, SP. p.145.1993.

SILVANO, R. A. M.; MC CORD, P. F. L.; LIMA, R. V.; BEGOSSI, A. When does this Spawn? Fishermen's local knowledge of migration and reproduction of Brazilian coastal fishes. Environ Biol Fish, v. 76 n. 3, 71-386. 2006.

TEIXEIRA, S. F.; MARIZ D.; DE SOUZA A.C.F.F.; CAMPOS S.S. Effects of urbanization and the sustainability of marine artisanal fishing: a study on tropical fishing communities in Brazil. - In: ErgenM. (ed.), Sustainable urbanization. Intech Open, p. 87- 114. 2016. 
TIES - The International Ecotourism Society (2015). What is ecotourism? Retrieved from <http://www.ecotourism.org/what-is-ecotourism>. Acessado em: 19 de novembro de 2018.

WTO - World Tourism Organization. UNWTO Annual Report 2017, UNWTO, Madrid. 2018.

ZAPATA, M.J.; HALI, M.C.; LINDO, P.; VANDERSCHAEGUE, M. Can communitybased tourism contribute to development and poverty alleviation? Lessons from Nicaragua. Current Issues in Tourism, v. 14, n. 8, 725-749. 2011.

\section{Agradecimentos:}

Os autores agradecem aos moradores da Barra do Una que participaram da pesquisa, as Professoras Orientadoras e a Coordenação de Aperfeiçoamento de Pessoal de Nível Superior - CAPES, pela concessão da Bolsa de Iniciação Científica através do programa PIC/CAPES ao primeiro autor.

Alison Peter Brito Dopona: Instituto de Pesquisas Cananéia - IPeC, Cananéia, SP, Brasil

E-mail: alissonpeterbio@gmail.com

Link para o currículo Lattes: http://lattes.cnpq.br/3876982170291807

Renato Xavier Araújo Prudêncio: Museu Nacional, Rio de Janeiro, RJ, Brasil

E-mail: renatoprudencio86@gmail.com

Link para o currículo Lattes: http://lattes.cnpq.br/6842085598327760

Milena Ramires: Universidade Santa Cecília - UNISANTA, Santos, SP, Brasil

E-mail: milena.ramires@hotmail.co

Link para o currículo Lattes: http://lattes.cnpq.br/0979037701910902

Mariana Clauzet: Universidade Federal do Rio de Janeiro, Rio de Janeiro, RJ, Brasil

E-mail:mariana.clauzet@gmail.com

Link para o currículo Lattes: http://lattes.cnpq.br/3795122699393224

Data de submissão: 22 de janeiro de 2019

Data de recebimento de correções: 25 de fevereiro de 2019

Data do aceite: 21 de agosto de 2019

Avaliado anonimamente 